\title{
Co-Evolution of Macro-Dynamics and Technological Change : an Alternative View on Growth
}

In: Revue d'économie industrielle. Vol. 105. 1er trimestre 2004. pp. 47-70.

\section{Résumé}

Cet article cherche à développer une approche endogène de la croissance permettant de mettre en évidence les interactions entre la dynamique macroéconomique et le processus de changement technologique. Nous baserons notre analyse sur deux courants hétérodoxes de la théorie de la croissance : l'approche dite de la croissance cumulative et la théorie évolutionniste. Le premier, développé à partir des travaux de $\mathrm{N}$. Kaldor, propose une approche macroéconomique de la croissance tirée par la demande. Le second considère la croissance comme résultant des processus micro-économiques liés à la technologie et à son évolution. Cet article propose une revue de ces deux courants de pensée, met en évidence leur complémentarité pour finalement les intégrer dans un même cadre d'analyse.

\section{Abstract}

This paper proposes an approach to endogenous growth considering the relationship between macro-dynamics and technical change. We draw upon two streams of literature : Cumulative causation and its macroscopic view of economic dynamics ; and Evolutionary economics and its focus on micro-determinants of technical change. This paper presents a survey of the formal representations of the growth process, identifies the possible bridges between these two approaches, and proposes a formal framework of analysis. Our daim is that merging these two distinct theories might offer a framework to consider the co-evolution of macro-dynamics and technical change.

\section{Citer ce document / Cite this document :}

Llerena Patrick, Lorentz André. Co-Evolution of Macro-Dynamics and Technological Change : an Alternative View on Growth. In: Revue d'économie industrielle. Vol. 105. 1er trimestre 2004. pp. 47-70.

doi : $10.3406 /$ rei.2004.3035

http://www.persee.fr/web/revues/home/prescript/article/rei_0154-3229_2004_num_105_1_3035 
Patrick LLERENA

BETA, université Louis Pasteur

André LORENTZ

LEM. Sant Anna School for Advanced Studies - Pisa and BETA, université Louis Pasteur

\section{CO-EVOLUTION OF MACRO-DYNAMICS AND TECHNOLOGICAL CHANGE: AN ALTERNATIVE VIEW ON GROWTH ${ }^{* *}$}

Mots-clés : croissance économique, changement technique, croissance cumulative, théorie évolutionniste.

Key words : Economic Growth, Technical Change, Cumulative Causation, Evolutionary Theory.

\section{I. - INTRODUCTION}

To analyse the relationship between technical change and macro-dynamics, one could directly refer to growth theory. Over the last years, numerous models have been developed in order to support the view that the emergence and diffusion of technical change not only affects but also drives economic growth and employment dynamics.

Among all these models, the New Growth Theory (NGT) is dominant in the literature. It stresses the importance of technical change, and increasing returns (that mainly drives the former) in growth dynamics. More recently, the NGT has also considered the effect of skilled biased technical change on employment and income distribution dynamics. In other words this literature mainly focuses on the effect of technical change on macro-dynamics.

(*) The research was supported by the EU, under the research programme "MACROTEC» (HPSE CT $1999(00014)$, and did especially benefit from discussions with and comments from Nick Von Tunzelmann (SPRU). Authors also thank C. Castaldi and the two anonymous referees for their comments. All usual disclaimers should nevertheless apply. 
However, the NGT rarely considers explicitly the reverse causality, meaning here the possible effect of macro-dynamics on technical change. One should rather say that the macro-influences (i.e. the behaviour of a representative consumer affecting firms' investments, along the balanced growth path) are set once and for all through the resolution of dynamic optimisation problems by the representative agents. But it seems a rather a specific way to speak about the influence of macro-dynamics on technical change.

Our aim is to explore another route and to propose an approach to the endogenous growth process. To do so, we examine two of the alternative approaches to growth theory to found in the literature. We focus on the PostKeynesian or Kaldorian approach to economic growth also known as Cumulative Causation growth theory, and on the Neo-Schumpeterian or Evolutionary theory developed around the work of Nelson and Winter (1982). On the one hand, this choice is guided by the rather complete analysis carried out by Kaldorians on growth as a self-reinforcing process linked to the strong interconnections between macro-dynamics and technological dynamics. On the other hand, we choose to consider the evolutionary approach, due to its focus on technological dynamics, their micro-foundations and their effect on macro-dynamics. As we argue later in this paper, these two approaches only propose partial analyses of the interactions between macro-dynamics and technological change. They nevertheless seem to complete each other, providing room for building an integrated framework.

The approach proposed intends to build a frame of analysis including explicit micro-foundations of the technological choices in a coherent macro frame to the growth process.

The paper is organised as follows: Section 2 presents Kaldor's work on growth and the foundations of the Evolutionary theory with its development in modelling economic growth. Section 3 is devoted to the discussion of the complementarities between these two approaches, the possible connections for providing a more complete framework to analyse the cross-effects of macro and technological dynamics and the few formal attempts to be found in the literature. Finally Section 4 sketches the lines of a growth model using a Kaldorian macro-frame together with evolutionary-like micro-dynamics for technical change.

\section{II. - ALTERNATIVE VIEWS ON ECONOMIC GROWTH AND TECHNICAL CHANGE}

\subsection{Kaldor's macroscopic approach of « cumulative causation »}

During his career, N. Kaldor's research covered a wide range of economic questions. We focus here on his contribution to the theory of economic growth and development of capitalist economies. If Kaldor's influence on the latter 
is undeniable, his contributions were scattered among his diverse works without, as he acknowledged himself, ever fully elaborating a « general theory $\gg$.

As far as this survey is concerned, one can point to three major statements to be found in Kaldor's work on economic growth: First, economic growth is a historical process. In this respect Kaldor reported a set of statistical regularities concerning long-run growth. Second, the undeniable influence of technical change and increasing returns on growth has to be considered as an endogenous process. Finally, aggregate demand is necessary to insure a self-sustainable growth process.

These three components of Kaldor's growth analysis form the basis for his verbal development of a « cumulative causation » approach to economic growth.

Introducing his 1957 growth model, Kaldor pointed out clearly the importance of modelling and understanding the economic growth process as being a historical process:

«A satisfactory model concerning the nature of the growth process in a capitalist economy must also account for the remarkable historical constancies revealed by recent empirical investigations » Kaldor (1957) (1).

In this respect, he underlines the following set of statistical regularities characterising the economic growth of capitalist economies:

- Industrialised economies are characterised by continuous growth in GDP and continuous increases in labour productivity.

- Industrialised economies are characterised by a continuous increase in the ratio of capital per worker.

- Profit rates on capital are constant.

- The ratio of capital to GDP is constant and regular over periods.

- Income distribution is constant over time. The share of labour income over GDP is constant over time; this implies that the growth rate of wages will be proportional on average to productivity increases.

- There exist non-negligible differences in growth rates of GDP and of labour productivity increases among economies.

(1) P. 260, as reprinted in « Essays on Economic Stability and Growth ».

REVUE D'ÉCONOMIE INDUSTRIELLE - $\mathrm{n}^{\circ} 105,1^{* x}$ trimestre 2004 
This set of stylised facts were probably the most influential contribution of Kaldor in the analysis of economic growth, cited by most growth theorists, from the «New Growth Theorists » to « Evolutionary economists », including naturally his direct followers.

From the mid-sixties onward, his conception of technical change, at the heart of the growth process, relies on the existence of increasing returns. The latter can be either static or dynamic (Kaldor $(1966,1972)$. Static increasing returns should be understood as the "classic » concept of increasing returns to scale, mainly at the firm level. They emerge in large-scale production systems due to labour specialisation and learning-by-doing (2). Dynamic increasing returns are the combination of two distinct dynamics. The first one is directly linked to the «technical progress function ». The resources generated are invested in production capacities, allowing for larger production scales, but also for more efficient ones due to the accumulation of more recent generation of machinery. The second effect refers directly to Young (1928), and relies on a macrolevel division of labour. The formal representation chosen to synthesize these increasing returns effects refers directly to the work of Verdoorn. The latter is nowadays known as the Kaldor-Verdoorn law. It links linearly the productivity growth rate to the growth rate of output via the Verdoorn coefficient, plus a constant term. This equation will be at the heart of the cumulative causation growth models.

The undeniable role of increasing returns in generating a sustained growth in production capacities of economies is not sufficient for Kaldor to explain growth processes. In this respect, he considers Young's (1928) analysis as incomplete. He (3) stresses the necessity to consider the demand factor in the analysis of economic growth. Demand provides the missing link between the increase of production capacities due to increasing returns and the generation of income growth.

Demand induces a « chain reaction » along the economy. The rate at which industries grow is related to the rate at which the others grow. Hence dynamic industries generate income, and then demand to be spread within the entire economy:

"The increases in demand for any commodity [...] reflects the increase in supply of other commodities, and vice versa » (Kaldor (1966) p. 19).

The nature of this « chain reaction » is rooted in the demand structure of the economy. The demand structure relies on three distinct but interrelated processes: Internal consumption, capital investment and external demand.

(2) It should be noted that the latter will constitute one of foundations of the NGT, but twenty years later.

(3) See Kaldor $(1966,1970,1972)$. 
«[B]oth the rate of growth of induced investments and the rate of growth of consumption become attuned to the rate of growth of the autonomous component of demand, so that [the latter] will govern the rate of growth as a whole 》 (Kaldor (1970)) (4).

For Kaldor, the whole growth process is then driven by this autonomous component of demand. This component in fact consists in the external demand. The growth rate of an economy is therefore connected to world income growth.

From these processes, Kaldor derives « the principles of cumulative causation » according to which economic growth is a self-reinforcing phenomenon generating the necessary resources to sustain itself over the long run. The cumulative nature of the growth process relies on a circular conception of the growth process and the co-evolution of two major dynamics: the existence of increasing returns and the increase of aggregate demand.

Dynamic increasing returns insure the long run growth of production capacities. These increasing returns are directly related to technical change. Technical change is itself generated within the economic system, through investments and the effect of the division of labour (5).

Following the Keynesian tradition, Kaldor considers economic growth as a demand driven process. An increase in aggregate demand will drive economic growth by generating the outlet for the increase in production capacities. Aggregate demand dynamics is related by a multiplier effect to the increase in its « autonomous » component (i.e. exports), stressing at the same time the importance of international trade.

These two main dynamics are interrelated. In generating income, aggregate demand dynamics create the resources to sustain investment and then to sustain dynamic increasing returns. This effect is synthesised by the KaldorVerdoorn law. Second, dynamic increasing returns sustain the competitiveness of the economy on international markets. The latter sustains aggregate demand dynamics through the multiplier effect. Economic growth is then a circular and self-reinforcing process, in the sense that "growth creates the necessary resources for growth itself » (Leòn-Ledesma (2000)).

This cumulative vision of the growth process leads Kaldor to consider two possible growth paths:

(4) As quoted by Boyer and Petit (1991).

(5) In this respect N. Kaldor achieved almost two decades before what will become the driving forces of growth for the New Growth Theory. 
- Growth within a « virtuous circle »: Dynamic increasing returns and the multiplier effect are such that, competitiveness and a sufficient aggregate demand can be sustained over time. Aggregate demand generates the resources sustaining dynamic increasing returns.

- Decline within « vicious circle»: Dynamic increasing returns are not sufficient to sustain competitiveness and/or the multiplier effect does not allow demand to sufficiently sustain dynamic increasing returns.

The entry to one or another path depends on the structural characteristics of the economies (i.e. among other factors, industrial and sectoral specialisation). These two growth schemes and the cumulative nature of the growth process recall the grip of history and the undeniable historical nature of growth analysis. They offer theoretical foundations to the existence of continuous, but significantly different, GDP and labour productivity growth rates among industrialised economies as reported in the 1957 paper's set of stylised facts.

Kaldor's « principles of cumulative causation » found a formalised counterpart in the regional growth model developed by Dixon and Thirlwall (1975). This model relies on two main dynamic processes. First, aggregate demand dynamics are driven by foreign income dynamics through exports dynamics and Hick's « super-multiplier ». Second technical change, represented by labour productivity increases is endogenously defined and linked to increases in production. It resorts formally to the Kaldor-Verdoorn law. This process aims to capture the influence of increasing returns (static and dynamic) as the engine for technical change. These two dynamics are then connected using price and exports dynamics; exports being a function among others of price competitiveness and price dynamics function of productivity increases. This model is completed by Thirlwall's 1979 paper that introduces in this framework an explicit balance of payment constraint (6) underlying the «super multiplier» in Dixon and Thirlwall (1975) and the exchange rate dynamics. From this constraint, Thirlwall constructs a trade multiplier in the Harrod tradition as the ratio between income elasticity to external demand and to internal demand for foreign goods. The structure of demand explicitly influences growth dynamics. Second, the exchange rate dynamics might partially absorb differences in competitiveness. It then neutralises any voluntary decrease in wages to accelerate growth through external demand channels linked to price competitiveness. Introducing this constraint tends to limit growth rate differentials but does not eliminate them. Moreover, the model seems to show the importance of short-term macro-economic conditions for growth (i.e. exchange rates). Amable (1992) develops the non-price competitiveness dimension of demand dynamics in the balance of payment constrained cumulative causation 
framework. Imports and exports dynamics representation becomes also linearly dependent on the « quality " competitiveness of the economy. The latter evolves through a learning-by-doing process. It increases with the accumulation rate of GDP. This specification reinforces at the same time the cumulative nature of the growth process and its path dependency.

Recent developments in the Kaldorian approach complete the traditional representation of technical change incorporating effects linked to the diffusion of technologies. Among others, one can point the models proposed by Amable (1993), Cimoli (1994) or Leòn Ledesma (2000). These modifications lead to the reduction of the differences in growth and technologies among economies. They also stress the importance of the macro absorptive capacities to be gained from external flows of technology to enable the catching-up mechanisms.

\subsection{Evolutionary Theorising on Economic Growth (7)}

The evolutionary approach to economic change has developed around the work of Nelson and Winter. Their book, " Evolutionary Theory of Economic Change ", published in 1982, is considered as the major foundation of modern evolutionary theorising on the economic analysis of technical change. Part IV of their book directly concerns the analysis of economic growth, building there the foundations of the evolutionary modelling approach of economic growth.

Evolutionary theory places itself in the direct line of Schumpeter's writings about long run economic development. It gives a central position to technological change, whether radical or incremental, due to the individual entrepreneur or to institutionalised R\&D activity. Evolutionary theory therefore places the source of technical change at firm level, in their investment behaviours and their learning capacities.

Following Schumpeter's idea, economic systems evolve out of equilibrium. The existence, according to him, of turbulence led by technical change cannot be understood in an equilibrium framework:

"[T]here was a source of energy within the economic system which would of itself disrupt any equilibrium that might be attained " (Schumpeter (1939)) (8).

Thus evolutionary modelling does not assume the a priori existence of equilibrium. If it exists, it has to emerge from economic dynamics.

(7) The title of this subsection intentionally mimics the title of the paper by Silverberg and Verspagen (1995).

(8) As quoted by Andersen (1994). 
Evolutionary economics prefers population dynamics to the representative agent assumption. These populations of agents are heterogeneous. They evol$v e$ in highly uncertain environments. These are due to imperfect information and/or the intrinsically uncertain nature of technologies. Moreover evolutionary economics assumes that agents are bounded rational. The uncertainty of the world they are evolving in is incompatible with substantial rationality. Behaviours are therefore limited to the application of routine decisions such as fixed and/or adaptive decision rules.

From the modelling perspective, Evolutionary economics directly refers to its namesake in natural sciences. The dynamics of economic systems rest on three major processes:

- Heterogeneity: Economic agents differ and in terms of behaviour, history, learning capacity, much as genetic characteristics in natural sciences.

- Mutation: Agents' characteristics evolve through time. This mechanism of mutation can concern behavioural patterns or technological patterns, among others.

- Selection: This process defines the survival or extinction of agents on the basis of given characteristics (i.e. competitiveness, profitability and so on...)

These three processes governing evolutionary dynamics are strongly interrelated. The selection process could only occur in a heterogeneous environment. The selection process tends to limit heterogeneity. To survive the selection process, heterogeneous agents have to mutate. Mutation then sustains heterogeneity. Evolutionary modelling cannot be considered without these interrelated processes.

Beyond these theoretical conceptions of economic dynamics, evolutionary growth models share a common willingness to reproduce historical growth patterns. As stated by Nelson and Winter (1982):

"The challenge to an evolutionary formulation [is to] provide an analysis that at least comes close to matching the power of the neo-classical theory to predict and illuminate the macro-economic patterns of growth $\gg$ (Nelson and Winter (1982) p. 206).

Evolutionary growth modelling does not try to model a balanced or stable growth path, but aims at reproducing, using theoretical models, some set of regularities and facts to be observed from the long-run growth patterns found in history (9). Nelson and Winter's (1982) seminal work explicitly aimed at reproducing and explaining Solow's (1957) data on total factor productivity

(9) Evolutionary growth models are based on a large empirical literature developed often by the same scholars. Even if we choose not to review this literature here, this fact deserves to be stressed. 
for the United States. Their main target was to model growth processes in an evolutionary way, generating "considerable diversity of behaviour at the level of firm » as well as an «[...] aggregative time path of certain variables [...] consistent with history but also compatible with Solow's results.

Nelson and Winter (1982) propose a growth model in which technical change and growth are driven by the micro-dynamics evolving within a population of heterogeneous and boundedly rational firms. These micro-dynamics rely on the interaction between selection and mutation mechanisms. Technical change is here the core of the mutation process. The entire macro-economic dynamics resides in the aggregation of these micro-dynamics. Hence in there formal approach, the authors consider economic growth as driven at the micro-level.

Nelson and Winter's (1982) contribution gave birth to an entire branch of evolutionary economics dedicated to the formal modelling of the economic growth process. The seminal quality of their work does not prevent this literature from being highly heterogeneous. Hence the core evolutionary principles, such as heterogeneity, selection and mutation processes, the assumption on the bounded rationality of agents and the Schumpeterian view that growth is driven by technical change as a micro-based process is commonly shared by this literature. But its formal representation differs among the approaches. Two main trajectories can be found.

A first trajectory is the one adopted by Chiaromonte and Dosi (1993), Dosi and Fabiani (1994) and Dosi, Fabiani, Aversi and Meacci (1994). These models share a disembodied conception of technical change. Technical change affects the use of production factors but is not directly linked to their accumulation. Technical change occurs at the firm level, and generates productivity increases. It results from innovation or imitation. These processes are stochastic, and quite similar to the one used in Nelson and Winter (1982). The success of $R \& D$ depends on the employment resources devoted to this activity. These models also are distinguished by their resort to a replicator based selection mechanisms, that unlike the Nelson and Winter do not imply that markets clear but rely instead on the distribution of the total demand among firms and economies relative to their competitiveness levels with respect to the mean. The formal definition of competitiveness slightly differs among models. In Chiaromonte and Dosi (1994), it is measured using prices and unsatisfied demand. In Dosi and Fabiani (1994) and Dosi et al. (1994) economies are open. Authors consider each economy as a sub-market. When firms act on their domestic markets, competitiveness is the inverse of price. When they operate on a foreign market it also includes the exchange rate. Exit occurs when the market share on a sub-market is lower then a given threshold. Each exit corresponds to the arrival of a new firm. Unlike Nelson and Winter (1982), these models consider an explicit macro-framework. All these models adopt a Keynesian vision. Total firm output is derived, and constrained by aggregate demand. In Dosi and Fabiani (1994) and Dosi et al. (1994), aggregate demand groups together domestic demand as a constant share of the total wage bill (the 
other share being devoted to imports), and external demand. These models introduce an explicit representation of growth rate dynamics of exchange rates, a function of the trade balance and external debt. Chiaromonte and Dosi (1993) consider a closed economy. Aggregate demand for consumption goods corresponds to the total wage bill. The aggregate demand for capital goods is derived from the production level of the consumption goods, constrained by demand. In all these models wages are set at the macro level. Their dynamics is linearly related to labour productivity, employment and consumption price growth rates. According to the authors the growth patterns generated through these models reflects the persistence of inter-firm asymmetries in productivity, profits and market shares, and is strongly related to micro-behaviours. No clear statement is made on the effect of the macro-frame on these patterns.

A second trajectory develops around Silverberg and Lehnert (1994), completed by Silverberg and Verspagen (1994, 1995, 1998). This family of models shares a common embodied conception of technical change. In these models production processes are represented using a capital vintage structure. Technical progress consists in the emergence of new «techniques » generated randomly, following a Poisson process at the economy level (Silverberg and Lehnert (1994)) or at the firm level (Silverberg and Verspagen (1994, 1995 and 1998)). Silverberg and Lehnert assume that the embodied level of productivity of each new technique is a fixed multiple of that of the best-practice technique. Technological progress leads to proportional improvements of labour productivity. Adoption of new technologies by producers then depends on the profitability of the techniques. In Silverberg and Verspagen (1994, 1995 and 1998), capital vintages are developed within firms. The probability for new vintages to be discovered depends on firms' $R \& D$ efforts and on their ability to benefit from spillovers from other firms' R\&D efforts. Firms' R\&D focus follows an adaptive decision rule. Firms choose to imitate when their profitability is « unsatisfactory » with respect to leading firms. Silverberg and Verspagen $(1995,1998)$ also introduce behavioural learning on R\&D investment choices. Firms learn to invest and renew these decision rules according to their own experiences or the others' experiences. The changes in decision rules can occur in two ways: Through experimentation (i.e. random renewing of their decision rules) or through imitation (i.e. adopting others' R\&D strategies). Unlike the models of the previous family these models assume a market clearing process (as in Nelson and Winter (1982)), setting prices. The survival of firms (in Silverberg and Verspagen (1994 to 1998)) or the diffusion of production techniques (Silverberg and Lehnert (1994)) is then based on their profitability. These models resort to a macro-economic framework directly inspired by Goodwin's (1967) model of growth and cycles, considering the co-evolution of employment and wages in explaining short-run cycles along long-run trends defined by the technical change process developed above. The main point of these models is to link the effects on grouwth patterns of the diffusion (Silverberg and Lehnert (1994), and generation of new technologies (Silverberg and Verspagen (1994, 1995 and 1998)) to bounded rational and adaptive learning behaviours and evolutionary micro-behaviours. 


\section{III. - TOWARDS AN INTEGRATED APPROACH ?}

The aim of this paper is to identify a formal framework to consider the coevolution of macro-dynamics and technical change. We previously presented two approaches in modelling the economic growth process. Each of them proposes only a partial analysis of the considered phenomenon. Our claim is then that by combining elements of these two approaches one might find a satisfying formal framework to consider explicitly the interaction channels between macroevolution and the micro-dynamics of technological progress. This section discusses the possibility of merging cumulative causation and evolutionary modelling of the economic growth process, in order to propose a micro-foundation for the Kaldorian growth model, and/or to specify the macro-economic impacts of industrial dynamics.

\subsection{Complementarities, Convergences and Divergences}

As we argue here, trying to integrate these two approaches in a unified framework to model the co-evolution of macro-dynamics and technical change mechanisms resides in the strong complementarities between the two approaches. Hence, one is responding to the weaknesses of the other. To stress this fact, let us recall briefly the main features of each of these analytical frames.

On the one hand cumulative causation presents a circular and self-sustained vision of the growth process. It is directly linked to the co-evolution of macrodynamics and technical change. These two processes are interconnected. First macro-dynamics is linked to technical change via the existence of dynamic increasing returns. Second technical change is strongly related to macrodynamics. Aggregate demand dynamics generates the necessary resources to sustain technical change. However this macroscopic analysis of the growth phenomenon relies on a schematic representation of the mechanisms driving technical change. This representation remains questionable, leaving aside the analysis of the technological processes themselves, especially with regard to recent developments in the micro-foundations of the technical change process.

Evolutionary modelling of economic growth, on the other hand, considers technical change as the core process driving macro-dynamics. This stream of literature concentrates on the emergence and diffusion of technologies and technical change within the economic systems. In line with Schumpeter, they consider that the whole economic dynamics responds to the micro-generated technological dynamics. The emphasis is then put on the analysis of micro determinants and behaviours of bounded rational agents. Macro-dynamics are the resulting processes of the aggregation of micro-dynamics. The status given to macro-dynamics excludes any explicit consideration about the influence of the latter on the technological dynamics. 
Hence where the Kaldorian approach lacks micro-foundations of the processes driving technological change, evolutionary theories provide an entire battery of micro-based dynamics. This emphasis on representing micro-dynamics at the heart of the emergence and diffusion of technical change however suffers from the lack of macro-foundations in the sense that it lacks a macro frame allowing feedbacks from the macro-dynamics to the micro-level. This is exactly where the Kaldorian approach completes the evolutionary modelling of the growth process. It emphasizes the importance of the macro-structure in absorbing and amplifying the growth impulses emanating from technological dynamics. These growth impulses generate income and therefore demand. And demand provides the resources to sustain technological dynamics.

These two approaches also share some common conceptions of the representation of the growth process that might support our willingness to integrate these two approaches in a common analytical frame.

First, these two streams of literature recognize the historical nature of the growth process. This historical nature is to be found first in the willingness to develop an empirically based theory. Modelling the growth process is based on a set of statistical regularities (i.e. Kaldor's stylised facts among others). Models aim first at reproducing observed growth path rather than generating eventually empirically testable balanced growth.

Second, Kaldorians as well as evolutionary theories on growth recognise the cumulative nature of the growth process. The latter can be linked to the cumulative and irreversible nature of technical change, and/or of knowledge accumulation, as in evolutionary approaches. It can also result from the complex interactions between macro-dynamics and technical change as for the cumulative causation approach. In any case the cumulative nature of the growth process relies mainly on the existence of dynamic increasing returns. The presence of these returns generates irreversibility in the technological evolution. This reveals the path dependent nature of the growth path.

These first two points of convergence naturally lead the two approaches to share a common rejection of the equilibrium concept. This leads them to consider « out of equilibrium » approaches to growth rather than the analysis of dynamic equilibriums or balanced growth paths.

Some similarities also emerge at the modelling level. Hence the way cumulative causation links exports dynamics to competitiveness seems to be an implicit selection process, close moreover to the replicator mechanism to be found in many evolutionary models, exports growing when competitiveness is higher than the average. It is nevertheless clear that this selection process remains partially implicit.

On the evolutionary side, an obvious bridge can be built with Kaldor's «technical progress function » while considering the modelling of the R\&D process. Hence, from Nelson and Winter (1982) to more recent models, technical change as resulting from the $R \& D$ process is strongly dependent on 
investments. These investments influence directly the probability of success of the R\&D activity. In short, technical change in evolutionary modelling could seem to rely on a stochastic version of the «technical progress function » as developed by Kaldor (1957).

Hence, we do not have only complementary but also convergent approaches. This convergence occurs first on the formal level, where they share common mechanisms linked to the growth process, such as the existence of dynamic increasing returns, explicit or implicit selection processes and the dependence of technical change on investments. Second, on the methodological ground, they commonly reject the equilibrium vision, considering the growth process as a historical, irreversible and cumulative process.

However, this apparent convergence hides an important implicit divergence. Kaldorians consider the growth process as resulting from interactions between demand and supply, aggregate demand dynamics and technical change. It implies that the macro-dynamics influence directly the hidden micro-dynamics underlying the Kaldor-Verdoorn law. The evolutionary approach, on the other hand, clearly considers economic dynamics as a bottom-up process. The dynamics of the economies are the direct consequence of micro-dynamics, and/or micro-behaviours. From an evolutionary perspective it is then inconceivable that the macro-dynamics influencing or affecting micro-dynamics are not emergent properties of other micro-dynamics. Here one might particularly think about the balance of payment constraint that allows Kaldorians to deduce from it aggregate demand as a function of external demand. The channels between macro and micro-dynamics have then to be clearly specified in any attempt at combining the two approaches.

\subsection{Evolutionary theorising on cumulative causation growth}

The frontiers between cumulative causation and evolutionary conceptions of the growth process are not, as argued previously, hermetically sealed. Recently contributions from both the cumulative causation and evolutionary literature appear to have attempted to overcome these frontiers. But only few models tend to explicitly introduce cumulative causation modelling in the evolutionary framework. These attempts mainly can be found in the works of Verspagen (1993, 2002).

Verspagen (1993, chap. 7) proposes what can be understood as an evolutionary re-reading of the cumulative causation approach to economic growth modelling. He represents growth within a multi-sectoral balance of payment constraint framework. The sectoral level is the smallest unit analysed here. Sectors of a given country differ in terms of goods produced. This would imply that the different sectors might experience different income elasticity within and among countries. 
A selection mechanism is explicitly introduced by a replicator equation, reflecting competition between foreign and domestic producers of a given sector. This reflects the idea that consumers, in the absence of quality differences (i.e. income elasticity), would prefer low-priced products. Production costs are endogenously determined as a function of both technological and macro-economic factors (10). Wages are determined through productivity growth and the unemployment growth rate, including some persistence, reflecting wage fixation as a path-dependent process. Exchange rates are quite rigid. They adjust slowly to ensure purchasing power parity in the long term. Thus, the selection process is a traditional evolutionary market selection process. In this respect Verspagen (1993) gives an explicit form top the implicit selection mechanisms that can be found in the Kaldorian models.

Another selection process applies at a more aggregate level, concerning this time the sectoral composition of aggregate demand. Hence, following Pasinetti (1981), Verspagen considers endogenous structural changes in the demand pattern. Demand elasticity (for each sector) with respect to income is a function of the distance between the actual demand level and a predefined satiation level. In this respect the model can generate patterns of sectoral specialisation producing uneven GDP growth rate (11). This second selection mechanism relates rather to the motions in long run structure of the economies rather then on market selection. This induces not only an evolutionary process in the allocating demand (i.e. market share) but also in structuring demand.

Verspagen's specification of technological progress is directly rooted in the Kaldorian tradition as it is modelled using the Kaldor-Verdoorn law. The model does not consider micro-founded technical change. In this respect Verspagen is rather closer to the Kaldorian tradition than to the Nelson and Winter search process approach. Mutation is therefore to be considered as a continuous and structurally defined process rather then a Schumpeterian-like unpredictable and disruptive motion as in the rest of the evolutionary growth literature.

This framework is developed to analyse the influences of a country's integration into worldwide trade and of its technological level on the growth rates constrained by trade balances. It analyses the effects of differences in technological competence between countries, on the growth rate differential among nations. The multi-sectoral aspect of Verspagen's analysis allows him to consider endogenous specialisation patterns. Cumulative characteristics of growth, technical change and wages tend then to bring about an explicit tendency

(10) Production costs depend negatively on the technological level of the sector and exchange rates, and positively on wage rates.

(11) A country leading in a given sector could grow more slowly then others if it is specialised in low growing sectors. 
towards industrial specialisation. This aspect was clearly assumed in the Kaldorian growth tradition, but is justified in this framework by an evolutionary selection process. This model tends to highlight clear relations between sectoral specialisation, technological change, and the growth process. These processes are both interdependent and self-reinforcing. Even if the model lacks of micro-foundations, it nevertheless represents the first attempt to consider evolutionary mechanisms such as heterogeneity and selection processes together with a cumulative causation framework.

Verspagen (2002) proposes a slightly different approach. His model uses a schematic multi-sectoral representation of the Dutch economy directly inspired by Keynesian macroeconomics. The structure of the economy explicitly considers the interaction structure among sectors, with the use of an input/output matrix as an aggregate representation of the production capacities. Following the Kaldorian tradition, Verspagen considers that long run growth is linked to external demand. The computation of the aggregate demand dynamics is deduced from the balance of payment constraint. Thus he obtains a reduced form for GDP growth rates including the sectoral interactions within what can be considered as a trade multiplier. The dynamics of external demand is modelled using a replicator equation. External demand is a function of the competitiveness of the economy.

The framework presented aims at analysing the effect of different scenarios on the macro-dynamics, through their diffusion along the economy. The author concentrates on two types of scenarios: competitiveness shocks and technological shocks. The first scenarios induce some modifications in the growth impulse generated by external demand dynamics. The second affect the factor coefficient of the input/output matrix. These shocks will affect the structure of the economy. For a given growth impulse generated by external demand, it is then the propagation of these growth impulses that will be modified. Technical change is not endogenously considered in this model, but its stochastic nature is closer to the Schumpeterian tradition than in Verspagen (1993). The paper mainly demonstrates that the macro-structure and its evolution itself strongly influence the macro-dynamics, by defining and constraining the diffusion channels of growth impulses.

\section{IV. - A CUMULATIVE CAUSATION GROWTH MODEL WITH EVOLUTIONARY MICRO-FOUNDED TECHNICAL CHANGE}

Surprisingly the cited attempts to bring together Schumpeter and Kaldor views on the growth process do not investigate the micro-aspects of technical change, introducing explicitly evolutionary micro-dynamics. More recently, in Llerena and Lorentz (2003), we introduced some evolutionary micro-foundations to technical change mechanisms in a balance of payment constrained growth model. This model provides some possible micro-foundations of the Kaldor-Verdoorn law, using a micro-framework in the Nelson and Winter tradition. Simultaneously the use of the balance of payment constraint framework 
imposes an explicit macro-structure to the traditional evolutionary growth modelling. The model remains consciously simplified. In line with Verspagen (1993), it aims at considering the mechanisms leading to growth rate differences among economies. The following section sketches the model and presents some of the results generated. A more detailed description of the model and the results is to be found in Llerena and Lorentz. (2003).

Formally, the model proposes a macro-economic framework directly in-line with Thirlwall's model of balance-of-payment constrained growth, defining through international trade relationship the dynamics of aggregate demand and GDP. Aggregate demand dynamics is a function of foreign aggregate demand growth through a trade multiplier, and of the economy's competitiveness on international markets.

Exports $\left(X_{j, l}\right)$, and imports $\left(M_{j, t}\right)$ are defined as in equation (1) and (2) as function of respectively foreign $\left(Y_{v, t}\right)$ and domestic income $\left(Y_{j, t}\right)$ and of foreign $\left(1-Z_{j, t}\right)$ and domestic $\left(Z_{j, t}\right)$ economies' market shares.

$$
\begin{aligned}
& X_{j, t}=\left(Y_{w, t}\right)^{\alpha_{j}} Z_{j, t} \\
& M_{j, t}=\left(Y_{j, t}\right)^{\beta_{j}}\left(1-Z_{j, t}\right)
\end{aligned}
$$

$\alpha_{j}$ and $\beta_{j}$ represent income elasticity. Economies market shares $\left(Z_{j, t}\right)$ are computed as the sum of all firms' market shares $\left(Z_{i, j, t}\right)$ defined through a replicator equation (3):

$$
Z_{i, j, t}=Z_{i, j, t-1}\left(1+\phi\left(\frac{E_{i, j, t}}{E_{t}^{-}}-1\right)\right)
$$

where $E_{i, j, t}$ represents price competitiveness of a firm and $\overline{E_{t}}$ the average price competitiveness. The parameter $\not$ can be defined as price elasticity.

The balance of payment constraint is such that imports growth rates equal exports growth rate. From the latter we deduce the following expression for the GDP growth rate (12) $\left(y_{j, t}\right)$

$$
y_{j, t}=\frac{\alpha_{j}}{\beta_{j}} y_{w, t}+\frac{1}{\beta_{j}}\left[\ln \left(\frac{Z_{j, t}}{Z_{j, t-1}}\right)-\ln \left(\frac{1-Z_{j, t}}{1-Z_{j, t-1}}\right)\right]
$$

Wages $\left(W_{j, t}\right)$ dynamics follows the economy's labour productivity $\left(A_{j, t}\right)$ dynamics proportionally, with one period time lag: 
with

$$
w_{j, t}=w_{j, t-1}\left(1+\left(\frac{A_{j, t}}{A_{j, t-1}}-1\right)\right)
$$

$$
A_{j, t}=\sum_{i} \frac{Z_{i, j, t}}{Z_{j, t}} A_{i, j, t-1}
$$

Equations (4) and (5) act like macro-constraints on the microevolution of firms. The first one defines the level of aggregate demand the firms have to face, while the second constrains production costs. These two components affect firm resources and therefore investment possibilities. But being at the same time a function of the micro-dynamics, these macro-dynamics are also constrained by micro-processes. These micro-macro interactions try to reflect and capture the idea of co-evolution of the microevolution of technical change and the macro-dynamics which define the mechanisms underlying the growth process.

The micro-level dynamics follows the evolutionary tradition. Technical change emerges at the firm level and depends on firm's investments. Firms production process is represented a Leontiev production function (equation (7)), with labour $\left(L_{i, j, t}\right)$ as unique production factor. Hence as in most evolutionary models in the short-run, firms exhibit constant returns to scale. Dynamic increasing returns are generated by technical change affecting labour productivity $\left(A_{i, j, t-1}\right)$. At each period, the output level $\left(Y_{i, j, t}\right)$ is determined by demand, and computed as a share $\left(\frac{Z_{i, j, t}}{Z_{j, t}}\right)$ of the aggregate demand $\left(Y_{j, t}\right)$.

$$
Y_{i, j, t}=A_{i, j, t-1} L_{i, j, t}
$$

Prices $\left(p_{i, j, l}\right)$ are set applying a fixed mark-up coefficient $\left(\mu_{j}\right)$ to unitary production costs (i.e. the wage bill per unit produced). Given the production function (7), prices are then expressed as in equation (8):

$$
p_{i, j, t}=\left(1+\mu_{j}\right) \frac{w_{j, t-1}}{A_{i, j, t-1}}
$$

Profits are defined as in equation (9). They are the only resources available for firms to finance their investments.

$$
\Pi_{i, j, t}=\mu_{j} \frac{w_{j, t-1}}{A_{i, j, t-1}} Y_{i, j, t}
$$

Therefore the more profitable the firms are the higher the investment potential. Investments play a crucial role for firms' gains in productivity. A first 
channel is through investments in capital goods $\left(I_{i, j, t}\right)$ as firms' labour productivity level $\left(A_{i, j, t-1}\right)$ is embodied in the capital vintages held by the firms, in the following way:

$$
A_{i, j, t}=\left(\frac{I_{i, j, t}}{\sum_{\tau=1}^{t} I_{i, j, \tau}}\right) a_{i, j, t-1}+\left(\frac{\sum_{\tau=1}^{t-1} I_{i, j, \tau}}{\sum_{\tau=1}^{t} I_{i, j, \tau}}\right) A_{i, j t-1}(1-\delta)
$$

Each capital vintage embodies productivity potential $\left(a_{i, j, t}\right)$. The firms' productivity level is then defined by the average of these potential productivity levels weighted by the share of investment in each vintage in the total capital stock. Note moreover that each period the pre-existing vintages decay at a given rate $(\delta)$.

Investments in capital goods $\left(I_{i, j, t}\right)$ correspond to a share $\left(l_{i_{2}, t,}\right)$ of the firms' income $\left(Y_{i, j, l}\right)$. These are constrained by profits $\left(\Pi_{i, j, t}\right)$, as depicted in equation (11).

$$
I_{i, j, t}=\min \left\{l_{i, j, t} Y_{i, j, t} ; \Pi_{i, j, t}\right\}
$$

Firms are boundedly rational. They apply the following decision rule (equation (12)) to set the share of income invested $\left(l_{i, j, t}\right)$ :

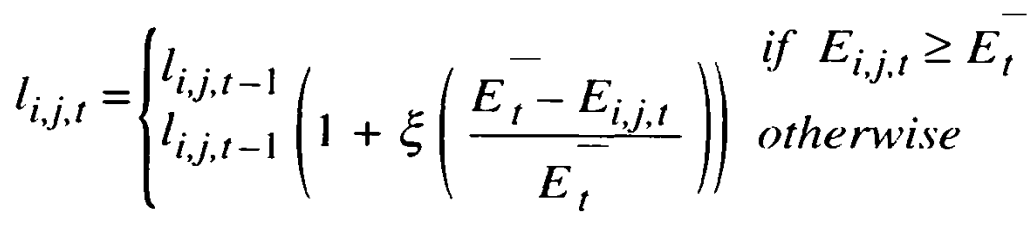

Hence, firms invest a fixed share of their income in capital goods unless their competitiveness is lower then the average one. Then they adapt their investment behaviour to their relative gap in competitiveness. Firms adopt the same investment routines as long as these remain successful.

The second channel through which firms' resources affect their productivity is investments in R\&D. The capital vintages are developed within firms. They result from firms $R \& D$ activity. The modelling of the $R \& D$ process is directly inspired by evolutionary models à la Nelson and Winter. The probability of success of the R\&D activity is function of their investments. Investments in $\mathrm{R} \& \mathrm{D}\left(R_{i, j, t}\right)$, correspond to the recruitment of researchers and financed by a share $\left(\rho_{i, j, t}\right)$ of firms income. Note that the cost of these investments $\left(\frac{1}{w_{j, t-1}}\right)$ therefore increases as productivity increases (through wages). In this sense, as productivity increases efficiency of $R \& D$ investment will decrease, the number of hired researchers decreases for a constant investment level, resulting in a decrease in the probability of success. This mechanism aims to capture the idea that when productivity is high, further increases become more difficult to attain. These investments are constrained by profits net of investments in capi- 
tal goods $\left(\Pi_{i, j, t}-I_{i, j, t}\right)$. In this respect firms first finance the introduction of existing vintages prior to investing in the development of new ones.

$$
R_{i, j, t}=\frac{1}{w_{j, t-1}} \min \left\{\rho_{i, j, t} Y_{i, j, t} ; \Pi_{i, j, t}-I_{i, j, t}\right\}
$$

As for investments in capital goods, the share of income devoted to $R \& D$ is also subject to adaptations in the decision rule. In this case, firms will increase their investment share $\left(\rho_{i, j, t}\right)$ to try to recover their technological gap with respect to the average productivity level $\left(A_{t}\right)$. These mechanisms are represented by equation (14).

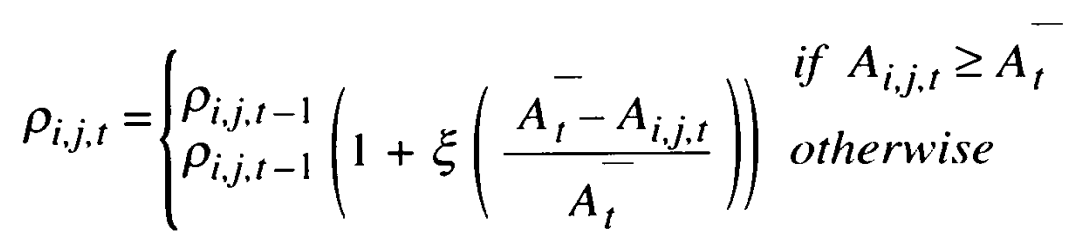

As said before, investments in $R \& D$, through the number of researchers hired increases the probability of success of $R \& D$. When successful, a new capital vintage has been developed. Its characteristics, namely the level of labour productivity it embodies $\left(a_{i, j, t}\right)$, is itself stochastically defined (equation (15) and (16)).

$$
a_{i, j, t}=\max \left\{a_{i, j, t-1} ; \hat{a}_{i, j, t}\right\}
$$

This level is drawn from a normal distribution (equation (16)) whose mean corresponds to the previous generation's productivity level $\left(a_{i, j, t-1}\right)$, and whose variance is defined by equation (17).

$$
\begin{aligned}
& \hat{a}_{i, j, t} \sim N\left(a_{i, j, t-1} ; \sigma_{i, j, t}\right) \\
& \sigma_{i, j, t}=\sigma_{j}+\chi_{j}\left(\max _{i, j}\left\{a_{i, j, t-1}\right\}-a_{i, j, t-1}\right.
\end{aligned}
$$

The variance includes a fixed level of technological opportunities $\left(\sigma_{j}\right)$, and a component corresponding to the technological gap $\left(\max _{i, j}\left\{a_{i, j, t-1}\right\}-a_{i, j, t-1}\right)$ between the firm's last developed vintage level of productivity and the frontier one, weighted by a parameter controlling for spillover's diffusion $\left(\chi_{j}\right)$.

We initially develop this framework to address the question of growth rate differences among the economies integrated in our artificial system. Our investigations focus on the effect of some key parameters in generating these divergence patterns. The detailed results might be found in Llerena and Lorentz (2003). Despite of the specific focus of this model, the results however constitute an interesting illustration of this alternative approach to growth mechanisms. 
As might be expected, the model generates growth patterns somewhere in between Kaldorian and Neo-Schumpeterian lines. Moreover, it exhibits a clear tendency for divergence rather then convergence among the economies. But these divergence patterns seem to be of a clearly different nature depending on the parameter configuration, leading to two significant divergence regimes (13):

«Sustained growth rate differences »: This regime is characterised by continuous and sustained differences in GDP growth rates among the economies. This regime emerges when considering heterogeneity in income elasticity $\left(\alpha_{j}\right.$ or $\left.\beta_{j}\right)$. In this case the differences in GDP are linked to the differences in the trade multiplier component of the GDP growth rate mechanisms. This regime is therefore demand driven, and relies entirely on the macro-dynamics. Note however that differences in GDP growth rates imply differences in economies' resources that also translate in differences in productivity. But these differences fade through time due to the decreasing potential in productivity increases implied by higher costs in $\mathrm{R} \& \mathrm{D}$. Moreover higher productivity levels do not imply sustainable gains in competitiveness due to wage dynamics; therefore the initial differences in income elasticity do not generate virtuous/vicious circles as Kaldorian literature would suggest but rather high/low growth paths.

- «Transitory growth rate differences »: This regime is characterised by phases of divergence in GDP growth rates that gradually fade through time. This regime emerges when considering differences in the level of technological opportunities among economies. These are translated into differences in productivity that generates differences in competitiveness and therefore GDP growth rates. These differences gradually disappear due to wage dynamics and the increasing in $R \& D$ costs linked to wages. This regime results in disparities in productivity and wages among the economies without sustained differences in GDP growth rates. This pattern is directly linked to the fact that through time wages disparities neutralise the effects of technological disparities, thus neutralising the possible gains in competitiveness.

These two growth regimes give an interesting illustration of the interactions between macro and micro-mechanisms, stressing first the importance of demand factors (i.e. for the first regime) in differences in growth and productivity, this independently from technological factors. Second, the stochastic

(13) A third, but less significant regime occurs when considering different settings of the parameter controlling spillover diffusion. This regime is characterised by differences in productivity growth leading to vicious circles and the collapse of the least competitive economies. This regime is less stable through simulations, and might rely on some misspecifications of the model, as we did not distinguish between innovation and imitation processes: leading economies might gain from the catching up experience of some lagging economies. This last regime disappears when a clear distinction between innovating and imitating firms is made (e.g. Lorentz (2004)). 
processes used at the micro-level being biased towards uneven technical change (i.e. for the second regime) only exhibit transitory divergence patterns. This feature of the micro-dynamics is neutralised by the wage dynamics process. Quite similar results can be found in Lorentz (2004) which proposes a multisectoral extension to the model presented above. This extension considers the mechanisms leading to patterns of sectoral specialisation and their effect on growth rates differences. The model generates results close to the two regimes as presented above, magnifying the role of wage dynamics in translating patterns of productivity differences among economies, naturally generated by the stochastic process to sectoral specialisation patterns, and to significant growth rate differences among economies. These differences are, as in Llerena and Lorentz (2003), only transitory when income elasticities are equally set among sectors and economies. This result corresponds to the second growth regime described above. Second, the model generates specialisation patterns directly linked to demand specifications (i.e. income elasticity differences among sectors), in this case economies concentrate their production in highly demanding sectors, even when the mechanisms of transmission of technological differences through wages is neutralised. This second pattern generated by the model also exhibits sustained differences in GDP growth rates among economies. High and low growth paths are then directly linked to the demand characteristics of the sectors in which economies specialise. This second pattern is highly similar to the first regime found in Llerena and Lorentz (2003).

One of the main interests of this approach is to be able to generate the two divergence regimes, allowing us to capture in the same model what can be understood as a Kaldorian regime and a Schumpeterian regime, which reflect two different mechanisms triggering growth rate differences. The sources of growth differences can be found at the macro and the micro levels. But it is in the interactions between macro and micro-dynamics that these sources are transformed into actual differences in growth. Therefore, not only micro and macro-dynamics matter in understanding growth mechanisms, but also the way they interact matter. This reinforces our claim that Kaldorian and Evolutionary theories presents clear complementary views. Developing and reinforcing the bridges between the two might help us to propose a more comprehensive view of the growth process.

The simulations also reveal the crucial role of wage dynamics in generating these results. This component is completely ignored by Kaldorians, being considered an exogenous variable. Most evolutionary models (see Nelson and Winter (1982), Dosi et al. (1994) among others) restrict it to a dynamic equation « closing » the model. Dosi et al. (1994) argue that growth and specialisation patterns emerge for the micro-dynamics. Wage dynamics set at the macro-level might be at the heart of the specialisation dynamics creating an inter-sector selection process. This mechanism is close to the one used in Lorentz (2004). It reveals another key mechanism to be investigated: wages dynamics, and labour market mechanisms in a larger extend as a linkage mechanism between macro and micro dynamics. 


\section{V. - CONCLUDING REMARKS}

In this paper we try to find an approach to endogenous growth processes, by analysing the co-evolution of macro-dynamics and technological changes. To achieve this goal, we choose to work with two heterodox approaches to economic growth analysis: the cumulative causation framework and the evolutionary theorising of economic growth.

Considering the possible interactions between macro and technological dynamics implies considering not only the way technical change generates productivity increases and then GDP growth. It also includes the analysis of the possible influence of macro-dynamics on technological change itself. Such an analysis then requires a framework that considers at the same time a clear understanding of the emergence and diffusion of technologies and of the macro-economic framework and mechanisms underlying the growth process. The two approaches seem, as we argued in this paper, to complete each other in describing these mechanisms. Hence, while the cumulative causation approach provides a complete description of the macro-mechanisms underlying the growth process, its description of technological dynamics remains schematic. However it helps by considering the channel through which technical change contributes to economic growth, generating income and then demand allowing GDP growth. But it also underlines the importance of macrodynamics in generating the resources necessary for technical change to occur. This last point might be one of the weaknesses of evolutionary models. On the other hand, evolutionory approaches provide a more complete analysis of the emergence and diffusion of technologies at a micro-level, stressing the importance of firm behaviours in terms of R\&D activity and investment behaviours.

This apparent complementarity encourages us to seek to integrate the two approaches within the same framework. Few formal attempts can be found in the literature that try to achieve this merging. Notable in this respect is the work by Verspagen (1993), that rather reconsiders the cumulative causation framework introducing explicit selection processes but without going into the micro-foundations of technical change. The model we propose in Llerena and Lorentz (2003), sketched in the previous section, considers the macro-framework deduced from the cumulative causation as a macro-constraint framing the micro-dynamics and hence technical change. The results illustrate the importance of integrating elements of these two literatures.

A possible limitation is that these attempts consider ad hoc macro-structures, acting on micro-dynamics as constraints. The major insight of these models, though, is to recall the importance of demand factors in the growth process, affecting the technical change mechanisms. The analysis of demand mechanisms still relies on income elasticity, exhibiting yet another black box to be opened. One therefore has to consider the micro-foundations of aggregate demand, making explicit market mechanisms as well as consumption behaviours and their evolution. 


\section{REFERENCES}

B. AMABLE, «Effets d’apprentissage, compétitivité hors-prix et croissance cumulative ». Économie Appliquée, 1992.

B. AMABLE. "Catch-up and Convergence: A Model of Cumulative Growth ». International Review of Applied Economics, 7: pp. 1-25, 1993.

E. S. ANDERSEN. «Evolutionary Economics: Post Schumpeterian contributions » Pinter Publishers. London and New-York, 1994.

R. BOYER and P. PETIT, «Kaldor's Growth Theories: Past, Present and Prospects for the Future " in E.J. Nell and W. Semmler (eds), 1991.

F. CHIAROMONTE and G. DOSI, "Heterogeneity, Competition and Macroeconomic Dynamics ". Structural Change and Economic Dynamics, 4:39-63, 1993.

M. CIMOLI, "Lock-in and Specialization (Dis) Advantages in a Structuralist Growth Model » in J. Fagerberg. B. Verspagen and N. Von Tunzelmann (eds.), 1994.

R. DIXON and A.P. THIRLWALL, "A Model of Regional Growth-Rate Differences on Kaldorian lines » Oxford Economic Papers, 1975.

G. DOSI and S. FABIANI, "Convergence and Divergence in the Long-Term Growth of Open Economies " in G. Silverberg and L. Soete (eds), 1994.

G. DOSI, S. FABIANI, R. AVERSI, and M. MEACCI, "The Dynamics of International Differentiation: A Multi-Country Evolutionary Model ». Industrial and Corporate Change, 1994.

G. DOSI, C. FREEMAN. R. NELSON, G. SILVERBERG. and L. SOETE, « Technical Change and Economic Activity ». Pinter, 1988.

N. KALDOR, «A Model of Economic Growth ». Economic Journal, December 1957.

N. KALDOR, «Essays on Economic Stability and Growth». Free Press, 1960.

N. KALDOR, "Causes of Slow Rate of Economic Growth in the United Kingdom ». Cambridge University Press, 1966.

N. KALDOR, "The Irrelevance of Equilibrium Economics". Economic Journal, 82: 1237$1225,1972$.

N. KAI.DOR, "The Role of Increasing Returns, Technical Progress and Cumulative Causation in the Theory of International Trade and Fconomic Growth ". Economic Appliquée. XXXIV (4), 1981.

M.A. LEÓN-LEDESMA, "Cumulative Growth and the Catching-Up Debate from a Disequilirium Standpoint ». Working paper. University of Kent, Canterbury, 2000).

J. LESOURNE and A. ORLEAN (éds), "Advances in Self Organization \& Evolutionary Economics ». Economica, Paris, 1998.

P. LLERENA and A. LORENT7, "Cumulative Causation and Evolutionary Micro-Founded Technical Change: A Growth Model with Integrated Economies ». LEM Working Paper, Pisa, 2003.

A. LORENTZ, "Sectoral Specialisation and Growth Rate Differences Among Integrated Economies ». LEM Working Paper 2004/06, Pisa 2004.

E. J. NELL and W. SEMMLER, « Nicholas Kaldor and Mainstream Economics: Confrontation or Convergence? » Macmillan, 1991.

R.R. NELSON and S.G. WINTER, «An Evolutionary Theory of Economic Change ». Harvard University Press, 1982.

L. L. PASINETTI, « Structural Change and Economic Growth: A Theoretical Essay on the Dynamics of the Wealth of the Nations ». Cambridge University Press, 1981.

J.A. SCHUMPETER, "Business Cycles: A Theoretical, Historical and Statistical Analysis of the Capitalist Process ». McGraw-Hill, 1939.

G. SILVERBERG and L. SOETE (eds.), "The Economics of Growth And Technical Change: Technologies, Nations, Agents ». E. Elgar, 1994.

G. SILVERBERG and D. LEHNERT, "Growth Fluctuation in an Evolutionary Model of Creative Destruction ». In G. Silverberg and L. Socte (eds), 1994.

G. SILVERBERG and B. VERSPAGEN, "Learning. Innovation and Fconomic Growth: A Long Run Model of Industrial Dynamics ». Industrial and Corporate Change, 1994.

G. SILVERBERG and B. VERSPAGEN. "An Evolutionary Model of Long Term Cyclical Variations of Catching Up and Falling Behind ». Journal of Evolutionary Economics, 1995. 
G. SILVERBERG and B. VERSPAGEN, « Economic Growth as an Evolutionary Process » in J. Lesourne and A. Orlean (eds), 1998.

R. M. SOLOW, "Technical Change and the Aggregate Production Function ». Review of Economics and Statistics, 39: 214-231, 1957.

F. TARGETTI, "Change and Continuity in Kaldor's Thought on Growth and Distribution ». In E. J. Nell and W. Semmler (eds), 1991.

A.P. THIRLWALL, "The Balance of Payments Constraint as an Explanation of International Growth Rate Differences ». Banca Nazionale del Lavoro, 32: pp. 45-53, 1979.

B. VERSPAGEN, « Uneven Growth Between Interdependent Economies: Evolutionary Views on Technology Gaps, Trade and Growth ». Avenbury, 1993.

B. VERSPAGEN, "Evolutionary Macroeconomics: A Synthesis between Neo-Schumpeterian and Post-Keynesian Lines of Thought ». The Electronic Journal of Evolutionary Modelling and Economic Dynamics, 2002.

A. YOUNG, «Increasing Returns and Economic Progress ». Economic Journal, 38:527-542, 1928. 